\title{
Monitoring during life cycle of bridges to establish performance indicators
}

\author{
Peter Haardt ${ }^{1}$, Ralph Holst ${ }^{2}$, \\ DOI: https://doi.org/10.5592/CO/BSHM2017.4.2 \\ ${ }^{1,2}$ Federal Highway Research Institute (BASt), Bruederstrasse 53, 51427 Bergisch Gladbach, Germany, \\ E-mails: ${ }^{1}$ Haardt@bast.de; ${ }^{2}$ Holst@bast.de;
}

\begin{abstract}
In future, additional and more detailed data are needed about the current conditions of bridges for preventive maintenance management. Monitoring procedures are not merely able to provide key performance indicators for a specific point in time, but also over a period. These KPIs must be selected in such a way as to permit substantiated statements about the present and future condition of bridges. For this reason, greater efforts must be made to define the significant KPIs for the various types of bridges, and show how these figures can be reliably determined. Both the COST Action TU1402, and TU1406 offer important approaches which, properly combined, can deliver substantial added value to the calculation and description of the condition of bridges in the interest of proactive maintenance management.
\end{abstract}

Keywords: preventive maintenance, bridge inspection, monitoring, life cycle, performance indicators

\section{Introduction}

An efficient road transport infrastructure is the prerequisite for guaranteeing mobility and economic growth. The increase in goods traffic recorded in recent years has led to a large proportion of bridges being pushed to the very limits of their capacity, and a further rise in traffic volume is predicted. It is also important to note that many road bridges are now getting on in years, and several of the old bridges are displaying specific structural shortcomings. Their increased age is accompanied by their deteriorating condition. All in all, these two opposing trends of strong increases in traffic volume on the one hand and increasing age on the other are producing a growing need for action regarding the maintenance and upgrading measures required. A wider scope of reliable information, which in part goes far beyond that traditionally provided, is required for the targeted planning, assessment and implementation of building measures in the life cycle of bridges. Here, it is important to identify the key performance indicators (KPIs) and to be able to substantiate those using verified figures. This is where monitoring can make an important contribution. The principal aspects of integrating monitoring into the life cycle of bridges are examined below.

\section{Monitoring as part of the current bridge maintenance regulations}

In addition to providing inventory data, the inspection of bridges in accordance with DIN 1076 [1] is of fundamental importance to the maintenance of road bridges from a legal, technical and fiscal perspective. The RI-EBW-PRÜF [2], in which the formula for assessing the condition of bridges during the bridge inspection under DIN 1076 has been documented, has been introduced as a further policy for road bridges. The bridge inspection is essentially conducted visually and at close hand. In line with the above policy, its purpose is to record and describe damage to structural elements and to assess the damage in terms of stability, safety for traffic and durability in conjunction with a condition assessment of the entire construction. The maintenance plans of the road authorities result from an analysis of these findings, and can therefore be viewed to be damage-based and thus reactive. This approach is documented for national highways in the rules on "systematic maintenance planning". DIN 1076 is considered to be the generally acknowledged technical standard, and the primary functions of bridge inspections are fixed in it:

- To detect defects and damage on time;

- As a result, to enable responsible bodies to rectify the above defects before greater damage occurs or traffic safety is impaired.

A specialist engineer who can evaluate both the structural stability and the constructional state of the bridges must be entrusted with the inspections. It must also be considered, however, that the result largely depends on the experience of the test engineer, and is therefore subjective. Added to this is the fact that the bridge inspection under DIN 1076 only represents a snapshot. Transient action (impact) and changes in condition are not taken 
into consideration. Due to the rigid inspection intervals, there is a temporal delay when detecting damage. Damage inside the bridge structures is also only diagnosed once it has become visible.

Legal aspects of the bridge inspection are also of key importance when classifying bridge inspections. For this reason, the federal government and "Länder" road laws and administrative regulations contain rules on the responsibilities of road authorities. These results in a special responsibility within the bridge inspection in that the bridge inspector must, where necessary, intervene directly [3]. This means that instrumental monitoring cannot be a complete substitute for bridge inspection at close hand, but must rather supplement it with aspects that are important in view of the growing need for information.

Particularly in view of the increased need for maintenance and upgrading of bridges, it is essential to acquire further information about action and resistance together with the associated findings derived from this, for example regarding system behavior and condition, reliability and the remaining service life. Continuously incorporating this information in the decision-making process makes it possible to move from a damage-based, reactive approach to fore-cast-based, preventive management maintenance.

Known faults in existing bridges and the growing traffic burden have in the recent past already led to a change in maintenance management at a national level. The calculation and upgrading to safeguard future requirements also takes place in bridges in the federal trunk road network where there is no specific damage pattern. Without supplementary regulations, the current calculation standards designed for the building of new bridges are unsuitable for evaluating the load-bearing capacity and serviceability of older bridges. The assessment must also consider the regulations and requirements at that time, the load-bearing system used, the materials deployed, the present condition of the bridge and practical experience to be able to make an accurate judgment about existing constructions; calculation guidelines have been compiled for this purpose [4]. These provide a self-contained method for calculating existing road bridges that makes use of the advantages of the semi-probabilistic approach in the current calculation standards. Spare structural capacity and building materials can be further exploited without compromising the level of reliability [5]. It is characterized by a graduated procedure in which verification management is modified step by step. Aspects of monitoring may be relevant in Steps 2 to 4 .

- $\quad$ Step 1: Verification in accordance with the Eurocode, i.e. as for a new build;

- Step 2: Verification with specific rules added to Step 1 that looks into action and resistance;

- Step 3: Verification taking account of the measurement readings taken on the bridge;

- $\quad$ Step 4: Verification using scientific methods.

Every calculation concludes with an engineer's assessment of results and assignment to verification classes:

- A (no restrictions regarding load-bearing capacity and serviceability with calculation according Step 1);

- B (no usage restrictions when applying the rules according to Steps 2 to 4);

- $\mathrm{C}$ (restricted conditions of use or compensation procedures).

The calculation results feed into a feasibility study for bridge upgrading based on the short-comings identified. If the results from the bridge inspection or usual engineering models only deliver imprecise or unsatisfactory information in terms of load-bearing capacity, serviceability or possible remaining service life, reliable and substantiated information can be obtained using monitoring. Additional information on action and resistance and on the system behavior obtained through monitoring may be integrated in calculation Steps 2 to 4 or calculation classes B and C. Monitoring as a compensation procedure is limited to calculation class C.

The cause of calculated excessive stress may lie in modeling that is too crude or not sufficiently realistic. Frequently, the load transfer on the actual system is more favorable than in the idealized model. Stress peaks may arise at individual points in calculation models, e.g. producing support joints that never occur in real life. The rigidity ratios of individual supporting elements or connections to them may also substantially influence the stress distribution. Measuring the actual strain that occurs under moving traffic produces clarity about the real load transfer, the position of the strain neutral axes of individual girders, contributory parts of structures etc.

With fatigue monitoring, not only the amount of stress or the stress intensity factor range are significant, but also the number of associated load changes. The actual traffic is greatly simplified for the calculated verification, however the differences between calculated and measured fatigue stress may be considerable. It generally makes sense to measure the strain or stress intensity factor ranges that actually occur under moving traffic. It is possible to conduct the verification of fatigue and remaining service life directly with the composite stress factors determined during measurement. 

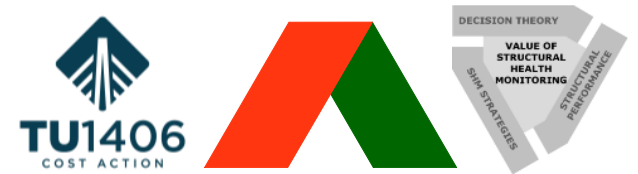

Where the calculated exceeding affects several structural elements of a construction or several components along a route section, it may be worth checking whether the load model used (e.g. LM1, BK60/30) corresponds to the actual traffic present. This should be recorded as accurately as possible to adjust the load model to the local traffic load.

The scientific methods in Step 4 are frequently based on complex modeling using very powerful finite element programs. The more complex a model of this kind is, the more opportunities there will be when entering diverse parameters for structural elements or building materials about which there is often no precise knowledge (e.g. Poissons ratio, the bond conditions etc.). Construction measurements are similarly effective when calibrating these complex models using the actual load-bearing or deformation behavior of the construction.

In the case of smaller bridges and especially when there are no as-built documents, load tests may be the last resort when it comes to verifying sufficient load-bearing capacity. Load-bearing capacity is generally calculated by recording a load deformation curve and monitoring the formation or initiation of cracks in critical areas during a cyclical increasing of the load. Tests of this nature require the definition of abort criteria which reliably exclude failure but are still close enough to the maximum load to produce a meaningful result. In addition to the load equipment, a corresponding monitoring system is also necessary.

\section{Monitoring during the life cycle of bridges}

Application areas for monitoring bridges are varied and occur throughout the service life; in practice, growing use can be seen in the following cases:

- Bridges where there is incomplete knowledge of risks (e.g. geological, seismic, environmental, during construction and during operation);

- Candidates for replacement or upgrading (e.g. with the aim of evaluating the need for intervention or assessing the efficacy of measures);

- Bridges with known shortcomings to extend the service life (e.g. as compensation procedure);

- Bridges of particular significance at the network level (e.g. the road network would be restricted to an unacceptable degree in the event of failure or limited availability);

- New construction methods, innovative designs, techniques or materials (e.g. as the basis for consents in an individual case, for approvals and to add to experience).

The incorporation of monitoring in maintenance management based on life cycle offers opportunities and benefits for road authorities and users of the road infrastructure in terms of safeguarding availability and extending the service life of bridges. Extending this to the entire life cycle entails looking at monitoring possibilities even during the planning phase, measuring and testing during construction and complete monitoring of the bridge in operation. The following potential is recognized in [6]:

- Guaranteeing the quality and checking the functions of bridges and their safety-related structural elements through continuous monitoring;

- Assessing the actual condition of bridges or bridge components based on neutral measurement data;

- Increasing safety due to the early detection of safety-related changes;

- Facilitating reliability analyses to safeguard availability;

- Optimizing repair and maintenance measures through the monitoring of ageing behavior and the development of damage patterns over time;

- Verifying the effectiveness of maintenance measures (including upgrading);

- Monitoring the conditions of use (e.g. complying with the maximum permitted gross vehicle weights);

- Determining the actual action and stress data to produce an input variable for further analyses of bridge management (e.g. fatigue monitoring, standardized calculations, updating of load models).

For informed statements and forecasts to be made about the condition, the load-bearing capacity and the remaining service life of the structural element/construction, it is crucial that the data collected are subjected to a structural analysis. As well as pure data logging, a monitoring system must always be seen in conjunction with an adapted data analysis and targeted assessment procedure. 
BASt currently has a research objective which involves developing innovative monitoring systems to provide extensive information in real time and for an integrated evaluation as the foundation for smooth operation and optimized maintenance management throughout the life cycle. This will deploy suitable sensor technology in sensor networks, combined with data analysis and assessment procedures. The use of measuring technology will provide previously unavailable information regarding the availability of the bridge and the damage and changes in condition to be expected. In combination with forecasting models and including the information from databases that has been available until now, the foundation will be laid for a preventive maintenance management focusing on reliability. Where necessary, an appropriate software system - or expert system - will give automated warnings to users, authorities and owners (adaptive structure, "Smart bridges") [7].

\section{Use of monitoring during the life cycle of bridges}

\subsection{Monitoring for quality assurance and function checks}

The life cycle management of bridges, in conjunction with the development of management systems (e.g. BMS [8]) and specific life cycle analysis procedures [9], has become a focus of attention. Life cycle management is understood here to be the integrated collection and analysis of all measures needed to construct, use and demolish a bridge. It is described as the realization and optimization of the analyzed processes of planning, construction and operation/maintenance, with the aim of maintaining the best possible condition of a bridge or a group of bridges in the network throughout their use phase at the lowest possible cost. Environmental, user and societal aspects may be relevant here in addition to the costs for the operator. Life cycle management comprises a calculation of service life during the planning phase, an adaption of service life models to practical implementation during the construction phase and structural inspections at intervals supplemented by the permanent monitoring of critical areas of the construction and the continuous updating of the forecast service life based on this during the operating phase.

Monitoring can, for example, be the foundation for optimized planning of maintenance measures to restore durability. The functionality and efficacy of safety and maintenance measures can then be checked even in inaccessible areas of the bridge, enabling verification about whether the success of a maintenance measure has in fact materialized and is having a lasting effect. Areas of use include maintenance measures aimed at preventing the penetration of pollutants or at maintaining or restoring the passivity of the reinforcement [10].

A further example concerns the area of bridge upgrading. The monitoring and checking of the effectiveness of the reinforcement measures conducted can, for example, include a survey of bridge reactions conducted for a limited period, combined with an assessment to evaluate the structural measures taken. This approach is important when there is a new construction method and innovative designs for which no reliable experience is yet available, whereby monitoring concepts centered on specific objects are needed here [11].

\subsection{Monitoring of action (impact)}

As well as providing information about traffic statistics, accurate knowledge of traffic load action is useful when deriving realistic load models and as a basis for a realistic estimate of the capacity utilization of bridges. In this context it is important for the determination of the reliability and remaining service life of the bridge. Another objective could be the direct registration of extreme loads and the derivation of traffic management measures. The information collected involves load spectra, vehicle loads, vibration coefficients, other effects such as temperature, wind speed and moisture as well as their classification according to intensity and frequency. With the help of special weighing equipment, e.g. WIM (Weigh-in-Motion) systems, weights and vehicle types can be determined, giving a good indication of load action [e.g. 12]. The accuracy that can be achieved largely depends on the accuracy of the sensors and on a reliable estimate of vehicle speeds. The sensor elements also react to dynamic effects arising from vehicle/carriageway interaction. By taking the additional logging of axle distances into consideration, e.g. using induction loops in the carriageway, it is also possible to obtain information about the axle loads of vehicles. Alternatively, deflection and strain measurements on bridge expansion joints can also be carried out to determine the traffic load [e.g. 13]. Speed can be measured using radar measurements or a number of laser photoelectric barriers.

During the practical application of bridge monitoring, impact is frequently not recorded directly but rather indirectly through the reactions of structures (deformation of supports, strain, open cracks) [refer to 12 for example]. The structural response regarding the causal loads in terms of size and pressure points is calculated for this. Previous approaches to calculate traffic load were restricted to linear elastic systems and to bridges with a narrow span. Complex algorithms are needed to analyze the measurement data, because the reactions of structures for several vehicles may overlap. This method has, however, now achieved a high degree of accuracy and reliability. The acting traffic loads are determined by permanently measuring the strain using a calibration function that describes the structural properties, for example the influence line. The influence line can be 

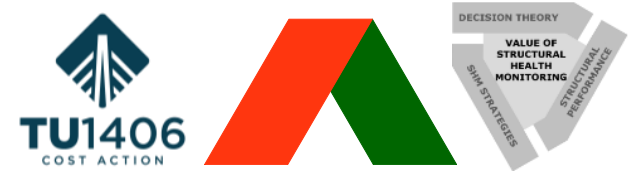

The Value of Structural Health Monitoring for the reliable Bridge Management

Zagreb 2-3 March 2017

calculated in advance using a test load or mathematically, and then classifying the general load data obtained in this way. If the dynamic system behavior is known, the traffic load can additionally be calculated from the dynamic structural response of the bridge, e.g. by working backwards on the basis of model calculations.

\subsection{Monitoring of the condition}

Bridges must be monitored regularly so that damage to them can be detected at an early stage and so their condition can be recorded. These tests and monitoring are currently carried out in accordance with DIN 1076. The use of bridge monitoring arises in the following cases [14]:

- Excessive deformation of the deck (measurement of deflection, strain, incline: thresh-old monitoring);

- Moisture penetration/efflorescence/washout on the deck (e.g. multi-ring electrodes: measurement starting from new build, frequency once a month, possibly threshold value procedure);

- Flaking with exposed corroded reinforcement and reduced cross-section through to the partial failure of the reinforcement (e.g. corrosion sensor: measurement starting from new build, frequency once a month);

- Depth of ingress of the chloride front (e.g. chloride sensors: measurement starting from new build, frequency once a month, possibly threshold value procedure);

- Checks of cracks and crack widths, taking impact areas into consideration (spray mist/sprayed water area/other area) through to crack movements under traffic loads (e.g. inductive path recorded, threshold monitoring);

- Leaky seal (e.g. multi-ring electrode: measurement starting from new build, frequency once a month.

Damage characterized, for example, by a change in material parameters and possibly in cross-section dimensions, e.g. due to corrosion of the reinforcement or concrete flaking, changes the resistance of the structural element at certain times and is therefore also relevant to load-bearing capacity. Common monitoring systems deliver results from which the damage on a bridge can either be obtained directly or can be used to draw conclusions about existing damage. No examples are known using reproducible information about the variables of a calculation on an undamaged system and the variables to be calculated from the measurement. There are no evaluations that provide stochastic descriptions of action or resistance. Monitoring systems leading to reliable statements regarding load-bearing capacity and remaining service life are only available for certain aspects [14].

\subsection{Monitoring safety-related system elements}

Monitoring with an early warning function is of great importance for bridges with an especially high risk and damage potential. The fundamental prerequisite here is a precise knowledge of the limit state as well as the nondestructive online analysis of the condition of the construction using objective and dependable measurement methods and decision-making tools. The type of monitoring strategy to be applied will depend on the specific problem. The following monitoring strategies are basically possible [15]:

- Predictive strategy: this requires adaptive models which adjust or can be adjusted to the respective state of the bridge; or

- Threshold monitoring: in this case, there is continuous monitoring of threshold values (e.g. limit to strain, cracks) without the need for a model.

The condition of the bridge can be assessed according to whether a defined threshold value (test threshold or alarm value) has been exceeded or fallen short of. Threshold values can, for example, be defined by the maximum permitted number of individual events or number of times they exceed or fall below a permitted range. It is usually necessary to know the zero state here, however. The threshold value may be directly defined for the measurement or a benchmark. If it is not possible to measure the benchmark directly, a corresponding measurement must be found. The important factor here is an unambiguous and so reversible connection between benchmark and measurement, using which the alarm threshold values of the measurement can also be transferred to the benchmark (and vice versa). A complex correlation often exists between the measurement and the benchmark or target value, which must be accounted for by adjustment or using a differentiated specification of the threshold values concerned, e.g. by specifying seasonal or temperature adjusted threshold values for deformation and strain. Alarm figures may be stipulated using upper and lower threshold values according to the marginal conditions and impact based on proof load(s) and on parameter or sensitivity studies.

In this context, the realistic simulation of the damage and bond behavior of reinforced concrete based on suitable material laws is an important aspect in establishing the limit or alarm thresholds. It is necessary to think about 
how the monitoring measure might influence the assessment of damage spread. Frequently, it is possible to achieve a good linear approximation of the damage trends between the as-built state and the end of use, so that the mathematically identifiable residual safety can be used as a good prediction of the remaining service life.

In the course of the monitoring concept there is also a need to establish whether and how an alarm (e.g. by email, text message, barrier blocking system, traffic lights etc.) may be triggered when the threshold value has been exceeded. This must also contain plausibility checks, control measurements or redundant measurement procedures which preclude a false alarm. The online monitoring must always be coupled with an emergency or action plan that states where the relevant measures are to be initiated if a limit value has been exceeded. The emergency plan in the form of a traffic light system in Figure 1 [16] offers an example of this.

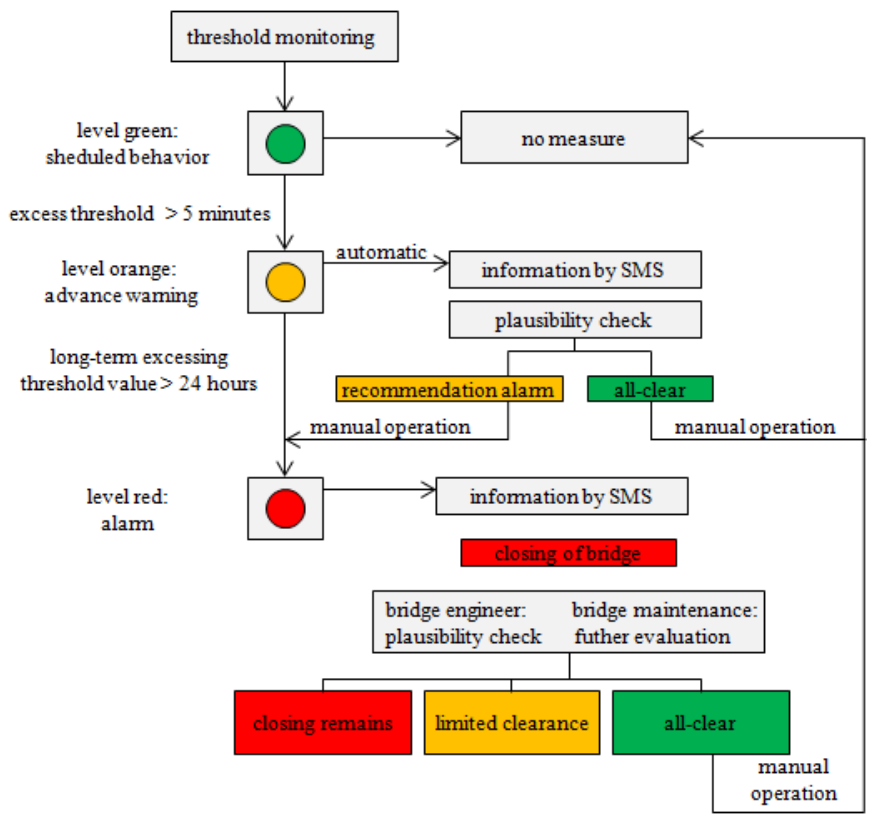

Fig. 1. Example of an alarm plan to regulate the responsibility in the case of exceeding limits for the threshold monitoring of a bridge [16]

The extraction of features from the measurement data recorded and the subsequent diagnostics constitute a key point of the monitoring system. There are basically two available models for monitoring constructions. When physical models are used, a parameter-based calculation model is adapted based on measurements of the actual structure. Due to their complexity, bridges are generally modeled using the FE method. The idealized bridge parameters such as dimensions and materials mean that these models are not able to reflect all aspects of actual structural behavior, however, so that the analytical forecasts then deviate from the data measured on the bridge. An updating and calibration of the unreliable parameters in the FE model (Finite Element Model Updating, model adjustment) is therefore required to achieve a further improved approximation of the actual structure; see [17].

The non-physical model is a data-based method used to recognize patterns in the measurement data. Nonphysical methods require training using learning techniques before their introduction. Mathematic algorithms are deployed that detect changes in a system using measurement data. For this, training data must first be accumulated through static or dynamic measurements to practice the reference condition. New measurements can subsequently be compared to this condition. Variations from the reference state suggest a change to the structure. Raw measurement data (e.g. vibration accelerations or structural element strain) or alternatively existing processed information (e.g. modal properties) is used to extract features. In order to obtain as many events as possible (impact of temperature and traffic), data from a sufficiently long period of time are needed. For data evaluation using cluster analysis, neural networks and regression analysis, see [17].

The advantage of the physical models lies in the potential realistic reflection of the construction to be monitored. This enables damage or a change in the behavior of the structural element to be detected, located and quantified. The preparation of physical models (and particularly the comprehensive FE models) is extremely timeconsuming. There is moreover a risk of obtaining no clear solution when identifying the bridge. Each individual bridge demands its own model adaptation, making it impossible to find any generalized monitoring measure. By contrast, measurement data can be evaluated extremely quickly using non-physical models, making these models 

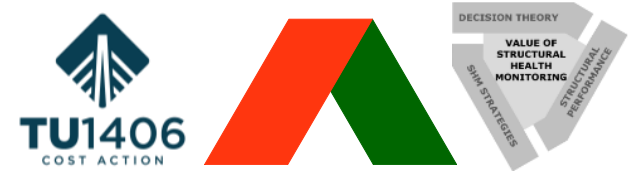

The Value of Structural Health Monitoring for the reliable Bridge Management

suitable for use in continuous monitoring of a bridge, where necessary in real time. One disadvantage is the large amount of measurement data needed for system training. As for implementation in practice, this model can largely be deployed independently of the bridge, and can therefore be used anywhere.

\subsection{Monitoring as compensation procedure according to the calculation guidelines}

The calculation guidelines have given engineers a tool for assessing the load-bearing capacity and serviceability of existing bridges. Compensation procedures are specified in the guidelines to safeguard further traffic use. A distinction is made between traffic compensation procedures and compensation monitoring procedures. Whereas the traffic compensation procedures are described in detail, the guidelines contain no explanations about compensation monitoring procedures and their effects on the reliability of the bridge.

In line with the reliability theory in civil engineering as the foundation for valid design rules, the necessary target reliability can be achieved again by gaining added safety through monitoring, thus compensating for the insufficient reliability level of the defective bridge. Initial approaches depending on the intensity of the monitoring are described in literature [e.g. 18], although the target values are only defined intuitively. Generally applicable methods for the application of measuring technology assisted monitoring concepts as compensation procedure have been developed in [19].

The key requirement for a compensation monitoring procedure is that it generates a sufficient safety gain. To support engineering practice, a quantification of the safety gain in a semi-probabilistic assessment concept is useful. In this concept, the safety gain is expressed through the influence of reduced partial safety factors and adapted characteristic variables. Based on probability theory, reduced partial safety factors for the "threshold monitoring" and the "action monitoring" were determined subject to the reliability of the monitoring itself.

The threshold monitoring describes the direct monitoring of the defective limit state. Exceeding a previously defined limit triggers an alarm mechanism. In the probabilistic approach, and assuming an adequate reaction to successful detection of damage, the probability of failure with threshold monitoring $\left(\mathrm{P}_{\mathrm{f}, \mathrm{U}, \mathrm{s}}\right)$ results from the intersecting set of the probability of failure without compensation procedure $\left(\mathrm{P}_{\mathrm{f}}\right)$ and the probability of failure of the threshold monitoring itself $\left(\mathrm{P}_{\mathrm{f}, \mathrm{S}}\right)$; see Figure 2 (left).

$\mathrm{P}_{\mathrm{f}, \mathrm{U}, \mathrm{S}}=\mathrm{P}_{\mathrm{f}} \cdot \mathrm{P}_{\mathrm{f}, \mathrm{S}}$

Threshold monitoring affects the actual limit state and therefore also all input parameters, enabling the partial safety factors to be reduced according to the probability of failure of the threshold monitoring. Provided that the structure failure itself is independent of the probability of failure of the threshold monitoring and with the help of full probabilistic analyses and consideration of the safety gain, the partial safety factors result as shown in Figure 2 (right).
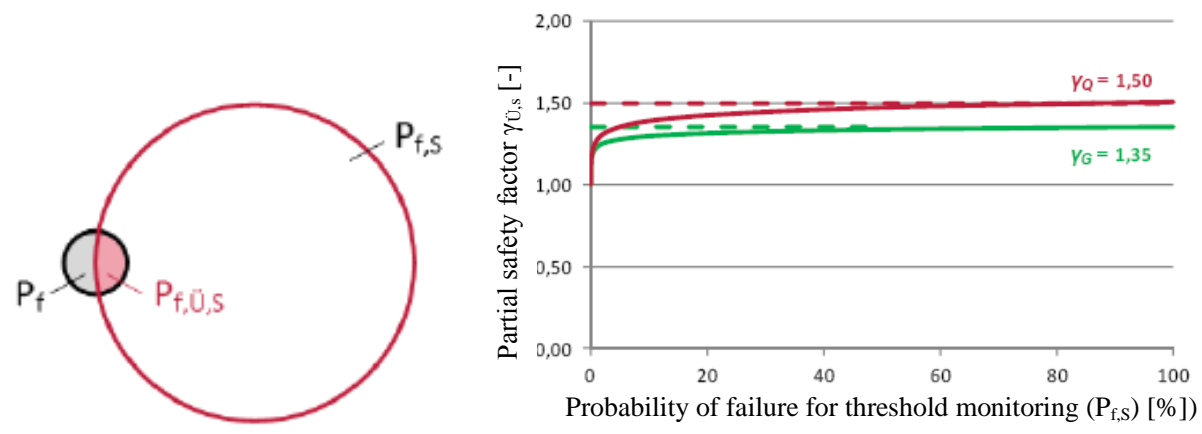

Fig. 2. Probability of failure of the threshold monitoring (left) and reduced partial safety factors $\gamma_{\mathrm{Q}}$ and $\gamma_{\mathrm{G}}$ due to threshold monitoring (right) [19]

The measuring technology design of threshold monitoring depends on the shortcoming in the existing bridge that needs to be compensated for. Experiences when calculating concrete bridges showed typical shortcomings in the SLS when verifying decompression and limiting crack widths and also in the ULS when verifying shear strength, transverse bending load-bearing capacity, fatigue and stress crack corrosion. Depending on the shortcoming, performance indicators with corresponding benchmarks or measurements must be identified and the corresponding measurement ranges defined. Suitable sensor technology that is coordinated to this must be selected (see [19]). 
With impact monitoring, potential impact from traffic is detected before it can actually affect the bridge. In the event of exceeding a previously defined limit, the bridge is closed. From a probabilistic perspective, impact monitoring means the elimination of uncertainty on the impact side above the prescribed impact limit, leaving a reduced probability of failure in relation to the probability of failure of the monitoring procedure itself; see Figure 3 (left). Reduced partial safety factors $\gamma_{\mathrm{Q} i, U, \mathrm{E}}$ in relation to the prescribed impact limit $\mathrm{Q}$ and the probability of failure of the impact monitoring $P_{f, E}$ are specified in Figure 3 (right). Here too, the calculation is made with the help of full probabilistic analyses and consideration of the safety gain.
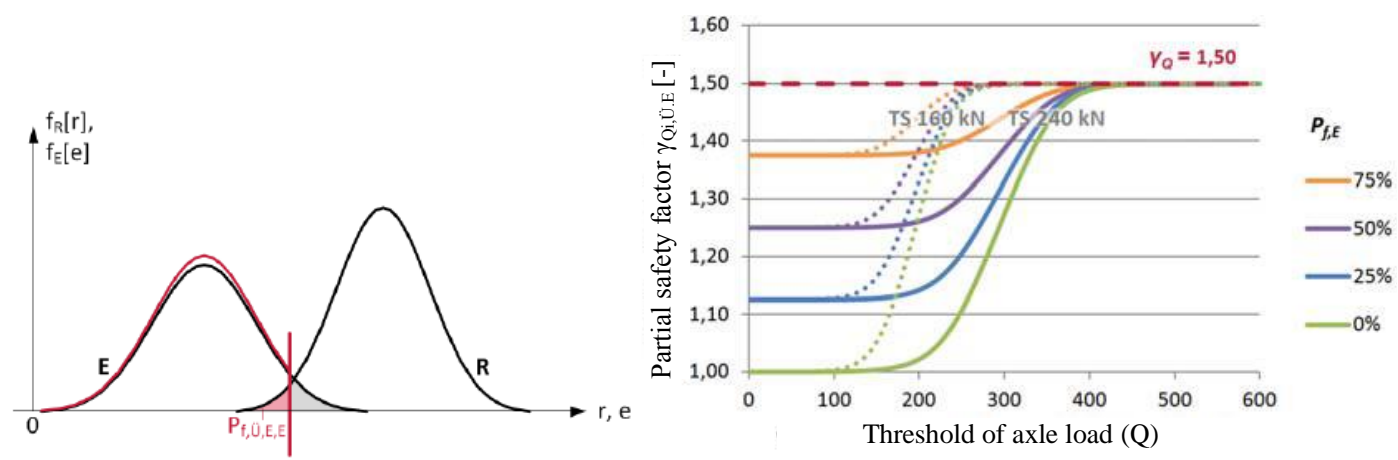

Fig. 3. Probability of failure during impact monitoring (left) and reduced partial safety factors due to impact monitoring (right) [19]

A series of case-by-case assessments - also concerning the reliability of the monitoring - is required so that the partial safety factors can be adapted to certain situations. Only with experience in practical applications is it possible to prepare a practical course of action and supplement the calculation guidelines with an annex of compensation monitoring procedures in the same way as already exists for traffic compensation procedures. Guidelines on specifying and monitoring threshold values are also highly relevant to practical application. Further research and above all more practical application are needed in the area of compensation monitoring procedures.

\section{Conclusions}

In future, additional and more detailed data are needed about the current conditions of bridges for preventive maintenance management. Monitoring procedures are not merely able to provide key performance indicators for a specific point in time, but also over a period. These KPIs must be selected in such a way as to permit substantiated statements about the present and future condition of bridges. For this reason, greater efforts must be made to define the significant KPIs for the various types of bridges, and show how these figures can be reliably determined. Both the COST Action TU1402, and TU1406 offer important approaches which, properly combined, can deliver substantial added value to the calculation and description of the condition of bridges in the interest of proactive maintenance management.

\section{References}

[1] DIN 1076 - Ingenieurbauwerke im Zuge von Straßen und Wegen; Überwachung und Prüfung, Ausgabe $11 / 1999$

[2] Bundesministerium für Verkehr, Bau und Stadtentwicklung: Richtlinie zur einheitlichen Erfassung, Bewertung, Aufzeichnung und Auswertung von Ergebnissen der Bauwerksprüfungen nach DIN 1076 (RIEBW-PRÜF), 2013

[3] Bundesministerium für Verkehr, Bau und Stadtentwicklung: Bauwerksprüfung nach DIN 1076 - Bedeutung, Organisation, Kosten, Dokumentation 2013, Eigenverlag

[4] Bundesministerium für Verkehr, Bau und Stadtentwicklung: Richtlinie zur Nachrechnung von Straßenbrücken im Bestand (Nachrechnungsrichtlinie), 2011

[5] Haardt, P.: Vom schadensbasierten zum zuverlässigkeitsorientierten Erhaltungsmanagement für Brückenbauwerke der Bundesfernstraßen. In: 2. Kolloquium Erhalten von Bauwerken, Technische Akademie Esslingen, 2011

[6] Kohlbrei, U.: Bauwerksmonitoring - Praxisbeispiele zum Mobilitätserhalt. In: 2. Brückenkolloquium Beurteilung, Ertüchtigung und Instandsetzung von Brücken, Technische Akademie Esslingen, 2016 

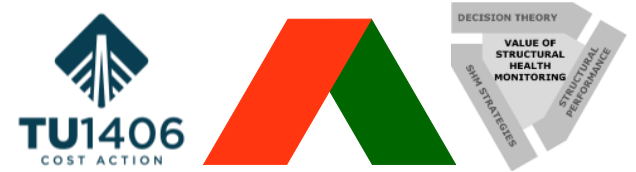

[7] Haardt, P.: Intelligente Brücken - Adaptive Systeme zur Informationsbereitstellung und ganzheitlichen Bewertung in Echtzeit. In: 3. Kolloquium Erhalten von Bauwerken, Technische Akademie Esslingen, 2013

[8] Haardt, P.: Konzeption eines Managementsystems zur Erhaltung von Brücken- und Ingenieurbauwerken. Berichte der Bundesanstalt für Straßenwesen, Heft B 25, 1999

[9] Müller, H. S., Vogel, M.: Lebenszyklusmanagement von Betonbauwerken. In: Tagungs-band 5. Symposium Baustoffe und Bauwerkserhaltung - Betonbauwerke im Untergrund: Infrastruktur für die Zukunft, Universität Karlsruhe, 2008

[10] Gehlen, C. Mayer, T.F., Schießel-Pecka, A.: Monitoring und Instandhaltung instandgesetzter Bauwerke. In: 12. Symposium Baustoffe und Bauwerkserhaltung, Karlsruher Institut für Technologie, 2016

[11] Zilch, K., Weiher, H., Gläser, Ch., Wunderlich, T., Schäfer, T.: Verstärken einer Spann-betonbrücke mit externer Vorspannung, SVB und eingeschlitzten CFK-Lamellen - Langzeitüberwachung einer innovativen Baumaßnahme mithilfe eines objektorientierten Monitoringkonzepts. In: DGZfP-Fachtagung Bauwerksdiagnose, praktische Anwendung zerstörungsfreier Prüfungen,. Berlin, 2006

[12] Lubasch, P.; Schnellenbach-Held, M.; Buschmeyer, W.: Computergestützte Identifikation von Verkehrslasten - Ergänztes Bauwerksmonitoring-, Bauingenieur 86, Heft 10/2011

[13] Marx, S.; von der Haar, C.; Liebig, J.P.; Grünberg, J.: Bestimmung der Verkehrseinwirkung auf Brückentragwerke aus Messungen an Fahrbahnübergangskonstruktionen, Bautechnik 90, Heft 8/2013

[14] Freundt, U., Vogt, R., Böning, S., Michael, D., Könke, C., Beinersdorf, H.: Einsatz von Monitoringsystemen zur Bewertung des Schädigungszustandes von Brückenbauwerken. Berichte der Bundesanstalt für Straßenwesen, Heft B 106, 2014

[15] Peil, U.: Lebensdauerverlängerung von Bauwerken mit Hilfe von Bauwerksüberwachung Bautechnik 80, Heft 9/2013

[16] Reiterer, M.; Praxmarer, L.; Kammersberger, A.: Maintenance und Monitoring, Dauermonitoring zur Optimierung der Nutzungsdauer einer Brücke, Beton- und Stahlbeton-bau 103, Heft 2/2008

[17] M. Schnellenbach-Held, M. Peeters, A. Brylka, S. Fickler, I. Schmidt: Überwachungskonzepte im Rahmen der tragfähigkeitsrelevanten Verstärkung von Brückenbauwerken aus Beton. Berichte der Bundesanstalt für Straßenwesen, Heft B 116, 2015

[18] K. Bergmeister, U. Santa: Brückeninspektion und -überwachung. In: Betonkalender 2004, Verlag Ernst \& Sohn, Berlin 2004

[19] C. Siegert, A. Holst, M. Empelmann, H. Budelmann: Überwachungskonzepte für Bestandsbauwerke aus Beton als Kompensationsmaßnahme zur Sicherstellung von Standsicherheit und Gebrauchstauglichkeit. Berichte der Bundesanstalt für Straßenwesen, Heft B 118, 2015 